\title{
Sensory and Shelf-life evaluation of a Food Multi-Mix formulated for rural children in South Africa
}

\author{
Oosthuizen, D., Oldewage-Theron, W.H. and Ebuehi, O.A.T.* \\ Institute of Sustainable Livelihoods, Vaal University of Technology, \\ Vanderbijlpark 1900, South Africa \\ *Address for Correspondence : Email: ebuehi@yahoo.com
}

ABSTRACT

\begin{abstract}
Food multi-mix (FMM) assists in providing ingredients balance from each food group within the formulation and to ensure maximum nutritional value. The objective of the study is to evaluate the sensory and shelf life of a food multi-mix formulated for rural children in South Africa.. The food multi-mix was formulated in conformity with the nutritional requirements of children . The multi-mix ingredients consisted of maize, which is a common staple in South Africa, spinach, sugar beans, carrots, pilchards in tomato sauce, as an inexpensive source of protein and oil. The ingredients were dried, pasteurized and cooled at room temperature, $25^{\circ} \mathrm{C}$. The FMM was ground into powder and immediately vacuum-sealed. The final recipes were standardized with $100 \mathrm{~g}$ of multi-mix . They included peanut-butter biscuit, sweet muffin and savoury muffin.The inclusion of these ingredients improved the nutritional value and boosted energy density.

The sensory evaluation of the FMM by the rural children was carried out using three attributes ; appearance, taste and smell, and a four-face hedonic scale representing very good, good, bad and very bad. The shelf-life of the FMM at room temperature, $25^{\circ} \mathrm{C}$, for a period of 28 days was determined . 10g of FMM was aseptically used and homogenized with $90 \mathrm{ml}$ of diluent ( buffered
\end{abstract}

\section{INTRODUCTION}

$\mathrm{F}_{\mathrm{b}}$ ood diversification is classified as a foodborne strategy which can be used to prevent micronutrient malnutrition on a long - term basis. Food multi-mix (FMM) development was pioneered by Gopaldas (1974), in which certain criteria were adopted (Cameron and Hofvander, 1987) to ensure accurate food formulation, safety, and affordability. Children do not always have sufficient knowledge to make adequate food peptone water ). Total aerobic plate counts on tryptone soy agar incubated at $25^{\circ} \mathrm{C}$ for $3 \mathrm{~h}$, were analyzed .Coliform and E.coli counts on a violet red bile 4-methyl umberlifery -beta-D-glucuronide agar and incubated at $37^{\circ} \mathrm{C}$ for $2 \mathrm{~h}$, were determined. The presence of B.cereus and $B$. aureus were determined on the $1^{\text {st }}$ day of the shelf life test.

Results of the sensory evaluation by the rural children showed that $83.9 \%$ of them preferred peanut butter and muffin, rated $73.1 \%$ for savoury muffin, and $94.5 \%$ for the sweet muffin. The children had preference for sweet snack items. The total aerobic plate count in the FMM tested over a period of 28 days were below $\log 4 / \mathrm{g}$ .Coliform and E.coli counts remained below $10 \mathrm{cfu} / \mathrm{g}$ throughout the shelf-life evaluation, while B.cereus and $S$. aureus were not detected. The presence of microbes detected in the FMM were less than 10 , which indicated that the FMM is safe for human consumption when stored at room temperature for 28 days

Data of the sensory and shelf evaluation of the formulated and prepared food multi-mix indicate that it is acceptable, safe, suitable and may improve the nutritional intake of children..

Keywords: Food multi-mix, sensory evaluation, , shelflife ,maize, peanut-butter , muffin

choices , and depend on decisions made by the food providers. School-aged children often consume more snack items during the day and as more money becomes available, then a higher amount of vending machine foods are consumed (Bennion, 1990; Mahan and Escott Stump, 2000). Studies completed by Steyn and Badenhorst (1993) suggested that nutrition programmes should be intended to improve the nutritional intake of children aged 6 to 14 years, 
to minimize expenses on sweets and cold-drinks daily.

Unfortunately, within rural communities due to lack of education, poverty, illiteracy, and inadequate health care services, most people consume foods with poor nutritional quality (Labadarios et al. 2005; Oldewage-Theron et al. 2005 ). The community of focus in this study is in the Vaal Triangle, situated about $70 \mathrm{~km}$ South of Johannesburg, South Africa. The community is faced with a problem of poverty, malnutrition and household food insecurity (Napier, 2003; Oldewage-Theron et al., 2005). The primary concern in this study is to develop a FMM suitable for children aged 6 to 13 years. The objectives of the study are to evaluate the sensory and shelf-life of a FMM formulated for rural children in South Africa. The sensory evaluation of the FMM would provide information on the acceptance and preference, while the shelf life study will assess its safety for consumption and storage.

\section{MATERIALS AND METHODS Principles of FMM formulation}

The FMM concept requires the use of local ingredients which are culturally acceptable and of low monetary value (Amuna et al., 2000), which was adhered to formulate the FMM used in this study.

The operating principles of FMM formulation comprises of four stages: (Cameron and Hofvander, 1987; Amuna et al. 2000; Zotor, 2002):

Stage 1: A four-step procedure for selection of ingredients from a staple source, a protein source,

ED and INQ are calculated as follows:

INQ = amount of nutrient $/ 4200 \mathrm{~kJ}$ reference of nutrient / $4200 \mathrm{~kJ}$ a selection of fruits and/or vegetables, which will supply ample vitamins and minerals, and a fat source.

Stage 2: This involves identifying limited nutrients of the target group of consumers and making a list of the foods most commonly consumed, and knowing whether these sources are locally available and economical. The total FMM should not be of more than five ingredients. A standard portion for 100g FMM is used. Using the food composition table, find a proportion of nutrient per weight selected. The total energy content was determined by multiplying carbohydrate and protein by 16.8 $\mathrm{kJ}$ and fat weight by $37.80 \mathrm{~kJ}$.

Stage 3: The formulation should yield an energy density (ED) between $15.12-18.90 \mathrm{~kJ} / \mathrm{g}(3.6-$ $4.5 \mathrm{kcal} / \mathrm{g}$ ), so that small quantities can be consumed daily and to provide maximum nutrient benefit. The index nutrient quality (INQ) should exceed or be equivalent to 1.0, so as to ensure a good quality of the product. The INQ is calculated by dividing the amount of nutrient in $4200 \mathrm{~kJ}$ of food with the allowance of nutrient per $4200 \mathrm{~kJ}$ of a reference food. The amount of nutrient is measured in grams and the allowance of nutrient is taken from the recommended dietary reference Intake (DRI) also measured in grams.

Stage 4: Once the ingredients have been combined, the ingredients are processed into powder form and the chemical analysis is completed, in order to determine the theoretical estimates and the experimental nutrient content. The FMM is then incorporated into recipes for sensory analysis, which will determine the acceptability (Cameron and Hofvander, 1987; Amuna et al 2000; Zotor, 2002). 
That is, calculate the INQ for vit. B2, if the experimental results indicate $0.2 \mathrm{mg}$ per $100 \mathrm{~g}$ at 1583 $\mathrm{kJ}$. EAR is $1 \mathrm{mg}$ per $9571 \mathrm{~kJ}$

$$
\begin{aligned}
\text { INQ } & =\underline{0.53} \\
& =1.44 \\
& =1.2
\end{aligned}
$$
$\mathrm{ED}=$ amount of energy from the FMM (kcal) weight of product $(\mathrm{g})$

That is , calculate the ED for $100 \mathrm{~g}$ FMM with an energy value of $423 \mathrm{kcal}$.

$$
\begin{aligned}
\mathrm{ED} & =\frac{423 \mathrm{kcal}}{100 \mathrm{~g}} \\
& =4.23 \mathrm{kcal} / \mathrm{g} \mathrm{-}
\end{aligned}
$$

The total, is then converted into kilojoules

The ingredients used for the formulation of the FMM, (Table1), were purchased through local retailers and included maize, combined with carrots and spinach, which are vegetables grown within the rural vegetable gardens. A legume, sugar beans, was used with the protein source, Pilchards in tomato sauce, which is common within the rural community households. The addition of oil was included to enrich the energy content. The total cost of the FMM was R1.50 (\$0.20) which was in line with the average R2.90 (\$0.40) per person to spend on a daily basis for all three meals (Oldewage-Theron et al., 2005).

During the preparation of the FMM, strict hygiene measures were employed to ensure the prevention of cross-contamination, as well as the maximum shelf-life. Surfaces and equipment were sanitised, and personal hygiene was adhered to at all times. This included the wearing of a hat, gloves, mask, laboratory jacket and the washing of hands each time in every new step or process. Safety was also maintained by the use of oven gloves.

Since the chemical analysis was carried in dry state, oil was omitted from the formulation, and each ingredients was increased with $1 \mathrm{~g}$,
(Table 2), to ensure a standard weight of $100 \mathrm{~g}$. The ingredients were dried individually at $65^{\circ} \mathrm{C}$. Dryness was confirmed, if the ingredients when pressed between the fingers crumbled. Pasteurization of the ingredients occurred at $85^{\circ} \mathrm{C}$ for $15 \mathrm{~min}$ (Wolf et al., 1990). The ingredients were cooled at room temperature before using it for the FMM preparation.

\section{Sensory Evaluation}

A child may not have sufficient knowledge and interpretation of the necessary characteristics required for the evaluation of food products. During the first sensory evaluation session, the primary school children interpreted the feel characteristics as the feel between two fingers (Oosthuizen, 2006). For this reason, the questionnaires for sensory evaluation by the school children were simplified to three sensory characteristics, namely, appearance, taste and smell. A four-face hedonic scale, as shown in Fig. 1 , was used representing very good, good, bad and very bad. Each face represented a score out of four, with very bad totalling one out of four. The final question of consumption was an indication as to whether the specific recipe item would be consumed again. 


\section{Shelf-life Evaluation}

The FMM was ground into powder form and immediately vacuum-sealed for the purpose of shelf-life evaluation at the Agricultural Research Council (ARC), an accredited laboratory. A representation of the mean ratios between dried and fresh ingredients, per gram is presented in Table 3. Only slight variations occurred during attempt 1 and 2 ,due to wastage during grinding and the carrots not being blanched during the second attempt, to retain more nutritional value. The shelf-life study of the FMM at room temperature, $25^{\circ} \mathrm{C}$ for a period of 28 days was carried out specifically at $0,3,7,14,21$ and 28 days. The recipe items, which consisted of a savoury muffin, sweet muffin and peanut-butter biscuit were individually vacuum sealed and sent for shelf-life evaluation for a period of seven days at room temperature.

An aliquot of $10 \mathrm{~g}$ of FMM was removed aseptically from the bag at the time of each analysis. The samples were homogenized in a Stomacher 400 (DHK Pty. Ltd.) with $90 \mathrm{ml}$ of diluents (buffered peptone water). The samples were analyzed for total aerobic plate counts on tryptone soy agar and incubated at $25^{\circ} \mathrm{C}$ for $3 \mathrm{~h}$. The samples were further analysed for coliform and E.coli count on a violet red bile 4methylumberlifery-âD-glucuronide (MUG) agar and incubated at $37^{\circ} \mathrm{C}$ for approximately $2 \mathrm{~h}$. The analysis of B.cereus (plated out on B.cereus selective base agar with egg yolk and B.cereus supplement, incubated at $37^{\circ} \mathrm{C}$ for $2 \mathrm{~h}$ ) and S.aureus (plated out on Baird Parker agar with egg yolk tellerie, and incubated at $37^{\circ} \mathrm{C}$ for $3 \mathrm{~h}$ ) were carried out on only the first day of the shelflife test.

The final recipe items were delivered to ARC-Microbiology and kept at $25^{\circ} \mathrm{C}$. $5 \mathrm{~g}$ sample was aseptically removed from each product and homogenized in a Stomacher 400 (DHK Pty. Ltd.) with $45 \mathrm{ml}$ of diluents (buffered peptone water). The samples were plated out for total aerobic count on tryptone soy agar and incubated for $72 \mathrm{~h}$ (Frazier and Westhoff ,1978) at $25^{\circ} \mathrm{C}$, and for yeast and mould on Rose Bengal agar and incubated for $72 \mathrm{~h}$. The muffins were plated at $0,1,2$ and 3 days, whereas the biscuits were plated at 0, 2, 4 and 7 days.

\section{RESULTS AND DISCUSSION}

A summary of the number of participants, which were mainly primary school children and food professionals, and feedback for all four evaluation sessions is shown in Table 4. The children showed a preference to the sweet items with responses of good and would definitely consume the recipe items again. The professionals made suggestions concerning characteristics of quality and portion size. Emphasis was placed to maintain a sufficient portion size suitable for consumption by children.

During all four evaluation sessions, the sweet muffin scored an average of 80.5 percent for appearance; taste averaged 62.5 percent, and the smell averaged 74.5 percent (Table 5). The results of the final evaluation session (Table 6), indicate that above 80 percent liked the peanut butter biscuit and the savoury muffin rated above 70 percent with the sweet muffin above 90 percent. The responses, very good and good, were summarised for each recipe item. The mean for the children was 54 and the amount preferring the recipes when considering appearance, taste and smell totalled 92 percent for appearance and both taste and smell were 87 percent. This observation is in agreement with previous reports by Gopaldas et al. in 1974, who reported that Indian infants preferred sweeter weaning multimixes. Studies by Zotor (2002), through the sensory evaluation of multi-mixes amongst 1000 children in Ghana, reported that a higher preference occurred for the sweet products, namely cakes and biscuits. 
Results of the shelf-life studies showed that the total aerobic plate count in the FMM tested over a period of 28 days were below $\log 4 / \mathrm{g}$ throughout the entire test period (Table 7). The counts were at $\log 3.8 / \mathrm{g}$ on day 0 and remained between a $\log 2 / \mathrm{g}$ and $\log 2.85 / \mathrm{g}$ on days $3,7,14$ and 21 , and again increased to $\log 3,6$ on day 28 . The E. coli and coliform counts remained below $10 \mathrm{cfu} / \mathrm{g}$ throughout the entire shelf life testing. Neither B.cereus nor S.aureus were detected on the first day of trial.

The FMM had a 28-day shelf-life. The counts were very low throughout the trial. The presence of organisms was read at $<10$, which implies their absence. The number of colony forming units (cfu) per sample in the FMM recorded the highest value of $6850 \mathrm{cfu}$ on day zero, while significantly $(\mathrm{p}<0.01)$ decreased to $700 \mathrm{cfu}$ in day 21 and then rises to $4550 \mathrm{cfu}$ in day 28 (Table 7).

The final recipes yielded peanut butter biscuits, sweet and savoury muffins. The total bacterial count of these recipes, as well as the yeast and mould count for the biscuit remained low throughout the seven-day shelf life evaluation (Tables 8, 9 and 10). The total colony forming count ranged between 55 and $180 \mathrm{cfu} /$ $\mathrm{g}$, which is within digestible limits and the biscuit can be stored for a seven-day shelf-life period at room temperature.

The total bacterial count for the sweet muffin as well as the savoury muffin stored at room temperature, increased from log $1.74 / \mathrm{g}$ and $\log$ $2.2 / \mathrm{g}$ respectively, to more than $\log 6 / \mathrm{g}$ on the second day. The yeast and mould count remained very low throughout the trial.

Due to the high colony forming units per gram, the sweet and savoury muffins can only be kept safe for human consumption at room temperature for only a 24 hour period, in most rural settlements.

\section{CONCLUSION}

Data obtained in the present study indicates that the formulation and development of the FMM is safe for human consumption when stored at room temperature for 28 days. The results of the sensory evaluation clearly show a preference to sweet snack items, which is common amongst children.

\section{ACKNOWLEDGEMENTS}

The authors are grateful to the ARC,Irene, South Africa, for the technical assistance and the Vaal University of Technology (VUT) and National Research Fund (NRF) for the funding of this project. Further gratitude is given to Dr Francis Zotor and Dr Paul Amuna for their input and guidance throughout this study.

\section{REFERENCES}

Amuna, P., Zotor, F., Suman, S., and Chinganga, Y.T. (2000). The role of traditional cereal/ legume/fruit-based multi-mixes in weaning in developing countries. Nutrition and Food Science, 13(3):116-122.

Bennion, M. (1990). Introductory Foods. $9^{\text {th }}$ ed., Macmillan Publishing Company, p. 1-69.

Cameron, M., and Hofvander, Y.(1987). Manual on feeding infants and young children. Oxford Medical Publications.p117-131.

Frazier, W.C., and Westhoff, D.C. (1978). Food Microbiology. $3^{\text {rd }}$ Ed. Tata McGraw-Hill Publ. Co Ltd., New Delhi, p17-65.

Gopaldas, T., Varakarajan, I., Greqal, T. and Shingwekar, A.G. (1974). Development of indigenous multi-mix for the preschool child. Indian Paediatrics. Journal of the Indian Academy of Paediatrics, p. 501-509. 
Labadarios, D., Steyn, N.P., Maunder, E., Macintyre, U., Gericke, G., Swart, R., Huskosson, J., Dannhauser, A., Vorseter H.H., Nesmuuni, A.E. and Nel, J.H. (2005). The National Food Consumption Survey (NFCS): South Africa, 1999. Public Health Nutrition, 8(5):533-543.

Mahan, K.L., and Escott-Stump, S.,(2000). Food, nutrition and diet therapy. $10^{\text {th }}$ ed., W.B. Saunders Company.

Napier, C. (2003): Nutritional status and food consumption patterns of children in the Vaal Triangle. M.Tech. Dissertation. Vaal Triangle: Vaal Triangle Technikon, Vanderbijlpark, South Africa. Unpublished data.

Oldewage-theron, W.H., Dicks, E., Napier, C.E. and Rutengwe, R. (2005). Situation analysis of an informal settlement in the Vaal Triangle. Development Southern Africa 22(1):13-26.
Oosthuizen, D. (2006). A Food Multi-mix to address malnutrition amongst primary school children living in Eatonside. M.Tech. Dissertation. Vaal University of Technology, Vanderbijlpark, South Africa. Unpublished data.

Steyn, N.P., and Badenhorst, C.J. (1993). The meal pattern and snacking habits of school children in two rural areas in Lebowa. Department of Human Nutrition. University of the North.

P5-9.

Wolf, D.I., Labuza, P.T., Olson, W.W. and Schafer, W. (1990). Drying foods at home. University of Minnesota Extension Services.

Zotor, F.B.(2002).Development and optimisation of nutrient-enriched traditional food multimixes for nutrition intervention in developing countries. Chatham: University of Greenwich, United Kingdom (M.Phil. Dissertation). Unpublished data.

Table 1: Formulation of the Food Multi-Mix

\section{Ingredient}

Maize,(96\% extract)

Sugar beans

Carrots

Spinach

Pilchards in tomato sauce

Sunflower oil

TOTAL

*g-grams on dry weight basis

\section{Weight (g)*}

42

16

15

12

10

5

100 
Table 2: Formulation of the Food Multi-Mix used for the nutritional analysis

\section{Ingredient}

Maize, $96 \%$ extract

Sugar Beans

Carrots

Spinach

Pilchards in tomato sauce

TOTAL

*g-grams on dry weight basis

\section{Weight $(\mathbf{g}) *$}

43

17

15

13

11

100

Table 3: Comparison of fresh , dried weights , fresh weight per gram and dried weight per gram*

\section{Attempt 1}

Ingredient

Maize

(1)

(2)

42

42

Sugar Beans

17

2000

17

Carrots

Spinach

Pilchards

210

2000

115

2440

510

*Weight expressed in g-grams;

Attempt 1

(1)fresh; (2)dried; (3)ratio

Attempt 2

(4)fresh; (5)dried; (6)ratio; (7)mean

Attempt 2

(3)

(4)

42:42

$17: 17$

$1: 9,1$

$1: 8$

$1: 4,8$
42

17

4500

7000

2975
(5)

42

17

470

814

676
(6)

42:42

$17: 17$

$1: 10$

$1: 8$

$1: 5,3$
(7)

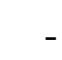

$-$

$1: 9,5$

$1: 8$

$1: 5,1$ 
Table 4: Sensory evaluation of recipes

\section{Recipe tested}

$\underline{\text { Sensory analysis } 1}$

Chocolate biscuits

Mealie meal muffins

Peanut butter biscuits

Coconut drops

Sensory analysis 2

Pumpkin fritters

Porridge (soft)/gravy

Vetkoek

Sensory analysis 3

Stiff porridge

Savour Muffins

Corn bread

Peanut butter biscuit

Sensory analysis 4

Peanut butter biscuit

Sweet and savoury

muffins
No. of Sensory Assessors

20 primary school children

Nine (9) professionals

Five (5) professionals

56 primary school children

\section{Remark}

Portion size toobig

Preferred sweet recipes; liked

Liked

Liked

Use yeast as a raising agent

Portion size too large

Too high oil content

Not of good colour and smell

Muffins and biscuits were good

Corn bread to dense Acceptable portion size

Acceptable in terms taste, appearance and smell.

Definitely consume again 
Table 5: Mean sensory scores of sweet muffin

\section{Evaluation 1 Evaluation 2 Evaluation 3 Evaluation 4 Mean \%}

$\begin{array}{llllll}\text { Muffin } & \% & \% & \% & \% & \% \\ \text { Appearance } & 79 & 69 & 85 & 89 & 80.5 \\ \text { Taste } & 63 & 69 & 55 & 78 & 62.5 \\ \text { Smell } & 73 & 69 & 75 & 81 & 74.5\end{array}$

Table 6: Mean percentages for sensory qualities of food multi-mixes, peanut-butter biscuit, muffin with apple and muffin with onion

$\begin{array}{lccc}\begin{array}{l}\text { Food multi-mix } \\ \text { (Recipe) }\end{array} & \text { Appearance }(\%) & \text { Taste (\%) } & \text { Smell (\%) } \\ \begin{array}{l}\text { Peanut-butter } \\ \text { biscuit; No = 56 }\end{array} & 92 & 87 & 87 \\ \begin{array}{l}\text { Muffin with Apple; } \\ \text { No }=55\end{array} & 92 & 87 & 87 \\ \begin{array}{l}\text { Muffin with Onion; } \\ \text { No }=52\end{array} & 92 & 87 & 87 \\ \end{array}$

Table 7: Total aerobic plates for E.Coli and Coliform counts of the Food multi-mix stored at $25^{\circ} \mathrm{C}$

Day of storage Total aerobic

g)

$\begin{array}{ll}0 & 6850 \\ 3 & 120 \\ 7 & 523 \\ 14 & 250 \\ 21 & 700 \\ 28 & 4550\end{array}$

Total aerobic E.coli $(\mathbf{c f u} / \mathrm{g})$ plate count (cfu/g*)

Coliform (cfu/g) plate count $(\log /$

*Colony froming units per gram of sample 
Table 8: Total aerobic plate, yeast and mould counts of peanut-butter biscuit stored at $25^{\circ} \mathrm{C}$

\begin{tabular}{|c|c|c|}
\hline Day of storage & Total aerobic plate count $(\mathbf{c f u} / \mathbf{g} *)$ & Yeast and Moulds $(\mathbf{c f u} / \mathbf{g})$ \\
\hline 0 & 55 & $<10$ \\
2 & 180 & 20 \\
4 & 120 & $<10$ \\
7 & 83 & $<10$ \\
\hline
\end{tabular}

*Colony froming units per gram of sample

Table 9: Total aerobic plate, yeast and mould counts of sweet muffin stored at $25^{\circ} \mathrm{C}$

\begin{tabular}{|l|c|c|}
\hline Day of storage & Total aerobic plate count $\left(\mathbf{c f u} / \mathbf{g}^{*}\right)$ & Yeast and Moulds $(\mathbf{c f u} / \mathbf{g})$ \\
\hline 0 & 55 & $<10$ \\
2 & $>3000000$ & $<10$ \\
4 & $>3000000$ & 10 \\
7 & $>3000000$ & 60 \\
\hline
\end{tabular}

*Colony froming units per gram of sample

Table 10: Total aerobic plate, yeast and mould counts of savoury muffin stored at $25^{\circ} \mathrm{C}$

\begin{tabular}{|c|c|c|}
\hline Day of storage & Total aerobic plate count $\left(\mathbf{c f u} / \mathbf{g}^{*}\right)$ & Yeast and Moulds $(\mathbf{c f u} / \mathbf{g})$ \\
\hline 0 & 168 & $<10$ \\
2 & $>3000000$ & $<10$ \\
4 & $>3000000$ & 10 \\
7 & $>3000000$ & 30 \\
\hline
\end{tabular}

*Colony froming units per gram of sample 
Fig 1: Sensory evalution from used by schoolchildren

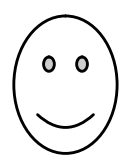

Very (4/4)

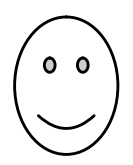

Good (3/4)

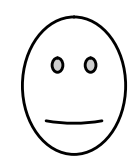

$\operatorname{Bad}(2 / 4)$

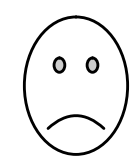

Very bad (1/4)

Please mark with a cross on the face which best describes your feelings about the following:

1. APPEARANCE
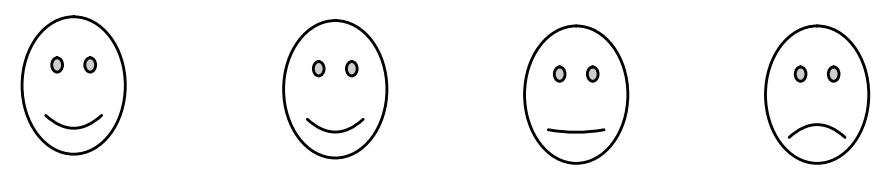

2. TASTE
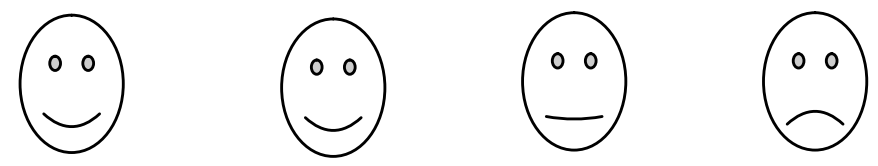

\section{SMALL}
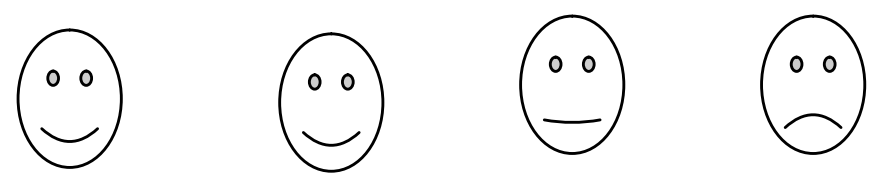

4. Would you eat it again?

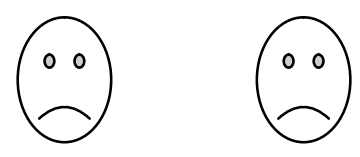

